\title{
Comparison of weekly and triweekly cisplatin regimens during concurrent chemoradiotherapy for nasopharyngeal carcinoma
}

Kailin Wang ${ }^{1 \dagger}$, Jun Dong ${ }^{2 \dagger}$, Shasha $\mathrm{He}^{3}$, Xia Wang ${ }^{1}$, Chang Jiang ${ }^{2}$, Pili Hu², Jiangui Guo ${ }^{4}$, Xiuyu Cai ${ }^{2 *}$ and Xicheng Wang ${ }^{1 *}$ (D)

\begin{abstract}
Background: We compared the survival outcomes and acute toxicities of weekly and triweekly cisplatin regimens during concurrent chemoradiotherapy (CCRT) in nasopharyngeal carcinoma (NPC) patients.

Methods: Patients were treated with CCRT alone. CCRT was initiated on the first day of RT. Cisplatin $30-40 \mathrm{mg} / \mathrm{m}^{2}$ was infused on days 1, 8, 15, 22, 29, 36 and 43 in the Weekly Group, while cisplatin 80-100 mg/m² was delivered on days 1, 22 and 43 in the Triweekly Group. The survival outcomes were revealed by the Kaplan-Meier method and Cox regression modelling to measure 5 -year overall survival (OS), disease-free survival (DFS), locoregional relapse-free survival (LRFS) and distant metastasis-free survival (DMFS).
\end{abstract}

Results: Ninety-three (28.9\%) patients received three to 7 cycles of cisplatin weekly (Weekly Group) and 229 (71.1\%) patients received two to 3 cycles of cisplatin triweekly (Triweekly Group). Five-year OS (weekly vs. triweekly, 96.7\% vs. $88.3 \%, P=0.036$ ) and DFS (weekly vs. triweekly, $90.7 \%$ vs. $80.5 \%, P=0.028$ ) were better in the Weekly Group than in the Triweekly Group. The weekly vs. triweekly 5 -year DMFS and LRFS rates were: DMFS, $96.7 \%$ vs. 91.4\%, $X^{2}=2$. $694, P=0.101 ;$ LRFS, $96.3 \%$ vs. $93.5 \%, X^{2}=1.317, P=0.251$. Cisplatin delivery regimen was not an independent prognostic factor. The incidence rate of acute toxicities was similar between the groups.

Conclusions: Compared with Triweekly cisplatin regimen, Weekly regimen may be a better choice during CCRT.

Keywords: Nasopharyngeal carcinoma, Cisplatin, Concurrent chemoradiotherapy, Survival

\section{Background}

Nasopharyngeal carcinoma (NPC) is a rare form of cancer, and is well known for its high mortality and morbidity in certain ethnic and regional populations, especially Southeast-Asian individuals. The incidence and mortality rate of NPC are about 2 to 3 times higher in men

\footnotetext{
*Correspondence: caixy_84@outlook.com; kailin0352@126.com ${ }^{\dagger}$ Kailin Wang and Jun Dong contributed equally to this work. 2Department of Integrated Therapy in Oncology, Sun Yat-sen University Cancer Center, State Key Laboratory of Oncology in South China, Collaborative Innovation Center for Cancer Medicine, Guangdong Key Laboratory of Nasopharyngeal Carcinoma Diagnosis and Therapy, 651 East Dongfeng Road, Guangzhou 510060, China

${ }^{1}$ Department of Oncology, The First Affiliated Hospital of Guangdong Pharmaceutical University, Guangdong Pharmaceutical University, 19 Nonglinxia Road, Guangzhou 510062, China

Full list of author information is available at the end of the article
}

than in women [1], and most patients with the condition exhibit locoregional or distant metastases at diagnosis. Advances in treatment technology and medicine have led to clear improvements in the local control and overall survival (OS) rates of NPC. Because of the radio- and chemo-sensitivity of the condition, patients receive systemic therapy based on concurrent chemoradiotherapy (CCRT). Even for locoregionally advanced NPC, good local control of diseases can be achieved by using this therapy $[2,3]$. Gradually, intensity-modulated radiation therapy (IMRT) has become the preferred mode of radiotherapy (RT) delivery because of its low incidence of severe complications.

Several previous studies have demonstrated the survival benefits of CCRT relative to RT alone [4-9].

(c) The Author(s). 2019 Open Access This article is distributed under the terms of the Creative Commons Attribution 4.0 International License (http://creativecommons.org/licenses/by/4.0/) which permits unrestricted use, distribution, and reproduction in any medium, provided you give appropriate credit to the original author(s) and the source, provide a link to the Creative Commons license, and indicate if changes were made. The Creative Commons Public Domain Dedication waiver (http://creativecommons.org/publicdomain/zero/1.0/) applies to the data made available in this article, unless otherwise stated. 
Triweekly cisplatin $\left(100 \mathrm{mg} / \mathrm{m}^{2}\right.$ infusion on Days 1,22 , and 43) is commonly used in these trials. However, compliance with this intensive regimen is poor because of the high incidence of acute toxicity $[7,9,10]$. To reduce acute toxicity, a weekly cisplatin regimen $\left(40 \mathrm{mg} / \mathrm{m}^{2}\right.$ infusion on Days 1, 8, 15, 22, 29, 36, and 43) was developed for use during CCRT [8, 11]. A recent report showed that smaller cisplatin doses administered more frequently during CCRT for head and neck cancers can result in a better tolerance of acute toxicities without compromising efficacy [12].

Although several investigations have compared the efficacies of weekly and triweekly cisplatin regimens during CCRT, adjuvant chemotherapy (AC) was performed after CCRT in these studies [13-15]. There are no head-to-head comparisons of weekly and triweekly cisplatin regimens in patients who received CCRT alone. In addition, there are no guidelines that definitively indicate which regimen is superior. Therefore, the purpose of this retrospective research was to compare the long-term survival outcomes and acute toxicities of weekly and triweekly cisplatin regimens in NPC patients who received CCRT alone.

\section{Methods}

This study involved retrospective analysis of 322 newly diagnosed and non-metastatic NPC patients, which treated by CCRT alone at the Sun Yat-sen University Cancer Center, Guangzhou, Guangdong, China, from January 2010 to November 2013. All patients were restaged on basis of the eighth edition of the American Joint Committee on Cancer (AJCC) staging system [16]. Histological subtypes of nasopharyngeal carcinoma were classified according to the WHO tumor classification rules, they are: keratinizing squamous-cell carcinoma (type I), differentiated non-keratinous carcinoma (type II), undifferentiated non-keratinous carcinoma (type III).

The procedures in the various studies involving human participants are consistent with the ethical standards established by national research commissions or institutions, as is the case with the Helsinki declaration and its subsequent revisions. The authenticity of this paper was verified by uploading the original data to the public platform of Research Data Deposit (www.researchdata.org. cn) and obtaining the approval number of RDD (RDDA2018000818).

\section{Enrollment criteria}

The principal eligibility criteria were:

- Initial treatment and no metastasis at diagnosis;

- treatment with only IMRT and cisplatin as the sole chemotherapy drug;

- adequate hematologic, hepatic, and renal functions;
- The concept of Stage-I-IVA disease defined by the eighth edition of the AJCC staging system [16].

The exclusion criteria were:

- History of prior malignancy or previous treatment for NPC;

- The existence of uncontrolled life-threatening diseases;

- Treatment with neoadjuvant or adjuvant chemotherapy;

- Radiotherapy techniques other than IMRT.

\section{Treatment}

All patients received the treatment of CCRT alone. CCRT was started on the first day of RT. The choice of weekly or triweekly cisplatin regimen was based on an evaluation of each patient's situation and aspirations by oncologists. Before thermotherapy with cisplatin, hydration was necessary for the Triweekly Group; dexamethasone plus 5-hydroxytryptamine type 3 antagonists were routinely used as antiemetic prophylaxis for all groups.

In the Weekly Group, 30-40 mg/m2 of cisplatin was infused on Days 1, 8, 15, 22, 29, 36, and 43. In the Triweekly Group, $80-100 \mathrm{mg} / \mathrm{m} 2$ of cisplatin was delivered on Days 1, 22, and 43.

IMRT was performed throughout CCRT. The prescribed cumulative radiation doses were 66-72 Gy/3033 fraction for the gross tumor volume of the nasopharynx, the doses of positive cervical lymph nodes were 64$70 \mathrm{~Gy}, \quad 60-63 \mathrm{~Gy}$ and 54-56 Gy for the high- and low-risk clinical target volume, respectively. RT took 67 weeks. Due to the limitation of dose tolerance mentioned in Radiation Therapy Oncology Group 0225 protocol, it is necessary to reduce the use of measurement as far as possible to avoid sacrificing the coverage of tumor target [17].

\section{Follow-up}

During the first 2 years after treatment, follow-up assessment was conducted at least every 3 months, every 6 months for the next three to 5 years, and annually thereafter until death. Every follow-up contained physical examination, nasopharynx and neck magnetic resonance imaging, nasopharyngoscopy, thoracic computed tomography, abdominal ultrasound or computed tomography, bone scan, and some hematological parameters, especially Epstein-Barr virus (EBV) DNA load.

\section{Survival outcome evaluation}

Follow-up was calculated from the date of diagnosis to the date of last follow-up or death. Overall survival (OS) was regarded as the time from first diagnosis to death, or the last follow-up. Disease-free survival (DFS) was 
regarded as the time from diagnosis to death, disease progression at locoregional and/or distant sites, or the last follow-up. Distant metastasis-free survival (DMFS) was regarded as the time from diagnosis to the first time observation of distant metastases. Locoregional relapse-free survival (LRFS) was regarded as the time from diagnosis to the relapse.

\section{Toxicity evaluation}

An assessment of toxicity was performed before and after each round of chemotherapy. The most serious toxic events that occurred during CCRT were counted. Acute toxicities were scored on the basis of the Common Terminology Criteria for Adverse Events version 4.03. [18]. Grade 3-4 adverse events (as severe events of acute toxicities) that occurred during CCRT were counted.

\section{Statistical analysis}

We used a chi-square test or Fisher's exact test to compare the clinical characteristics and acute toxicity rates of the two treatment groups. We used Student's $t$-test to compare the cumulative dose of cisplatin in each group. Using the Cox proportional hazards regression model to analysis the clinical variables, and variables with $P$-values $<0.05$ were used in the following multivariate analyses. Survival was measured by the Kaplan-Meier, and the differences between curves were analyzed by the log-rank test. Statistical analysis was performed using SPSS version 19.0 (IBM Corp, Armonk, NY, USA). Each statistical test was two-sided; $P<0.05$ was deemed to have statistical significance [19].

\section{Results}

\section{Baseline characteristics}

Registered a total of 322 eligible patients, of them, 93 (28.9\%) patients required weekly cisplatin treatment (Weekly Group) and 229 (71.1\%) received triweekly cisplatin (Triweekly Group) during CCRT. The median age among the whole cohort was 44 years old. The plasma pre-treatment EBV DNA load cutoff value of 4000 copies/ml was based on a previous study, where the use of this value led to significant risk stratification [20]. Sixty-two $(66.7 \%)$ patients in the Weekly Group and 146 (63.8\%) in the Triweekly Group had a plasma EBV DNA load $\leq 4000$ copies $/ \mathrm{ml}$, and $31(33.3 \%)$ patients in the Weekly Group and 83 (36.2\%) in the Triweekly Group had a plasma EBV DNA load higher than the cutoff value. The Weekly and Triweekly Group means of cumulative cisplatin were $190.54 \mathrm{mg}$ and $202.97 \mathrm{mg}$, respectively $(P$ $=0.062$ ). Most of the patients were non-smokers, non-drinkers, suffered from non-keratinizing undifferentiated carcinoma (type III), and were diagnosed with Stage-III-IVA disease. There were no significant differences in baseline demographics and disease characteristics between the two groups. Details are shown in Table 1.

\section{Survival outcomes}

The median follow-up time for the entire cohort was 60.2 months (range, 7-96.4 months). The overall 5-year OS, DFS, DMFS, and LRFS rates were 90.8, 83.8, 92.9, and $94.3 \%$, respectively. The 5 -year OS rate of the Weekly Group was better than that of the Triweekly Group (Fig. 1a). The log-rank test revealed that there was a significant difference in 5-year OS between the groups (weekly vs. triweekly, $96.7 \%$ vs. $88.3 \%$, $\chi^{2}=4.382$, $P=0.036)$. The 5 -year DFS rates of the Weekly and Triweekly Groups were 90.7 and $80.5 \%$, respectively, and exhibited a significant difference between the groups ( $x^{2}=4.831, P=0.028$; Fig. $1 \mathrm{~b}$ ). Regarding the weekly vs. triweekly 5-year DMFS and LRFS rates, there were no significant differences between the two groups (DMFS, $96.7 \%$ vs. $91.4 \%, X^{2}=2.694, P=0.101$; LRFS, $96.3 \%$ vs. 93.5\%, $\chi^{2}=1.317, P=0.251$; Fig. $1 c$ and $\left.d\right)$.

\section{Acute toxicities}

There was a similarity in the incidence of grade 3-4 treatment-related adverse events, such as hematologic and non-hematologic toxicity events, between the Weekly and Triweekly Groups. Hematologic toxic events were more frequent in the Weekly Group than in the Triweekly Group. Seven (7.5\%) patients in the Weekly Group and eight (3.5\%) in the Triweekly Group exhibited Grade 3-4 thrombocytopenia. However, there was no significant difference in the incidence of Grade 3-4 thrombocytopenia between the groups $(P=0.12)$. Two $(2.2 \%)$ patients in the Weekly Group and one (0.4\%) in the Triweekly Group developed Grade 3-4 anemia, and 21 (22.6\%) patients in the Weekly Group and 38 (16.6\%) in the Triweekly Group developed Grade 3-4 leucopenia. There were no significant differences in the incidences of Grade 3-4 anemia $(P=$ $0.147)$ and Grade $3-4$ leucopenia $(P=0.208)$ between the groups. The incidence of Grade 3-4 non-hematologic toxicities, including in the mucosa, skin, nausea-vomiting, creatinine-increased and ototoxicity were similar between the groups. There were no deaths due to treatment. The toxicities after the completion of CCRT in each group are listed in Table 2.

\section{Univariate and multivariate analyses}

Pre-treatment EBV DNA load ( $\leq 4000$ copies/ml vs. > 4000 copies $/ \mathrm{ml}$, hazard ratio $[\mathrm{HR}]=3.402$, 95\% confidence interval $[\mathrm{CI}]=1.525-7.589, P=0.003$ ) was an independent prognostic factor for OS. The cisplatin delivery regimen (weekly vs. triweekly, $\mathrm{HR}=2.795$, 95\% $\mathrm{CI}=0.836-9.35, \quad P=0.095)$ was not an independent prognostic factor for OS. Regarding DFS, pre-treatment 
Table 1 Baseline characteristics of the 322 patients who received concurrent chemoradiotherapy

\begin{tabular}{|c|c|c|c|c|c|c|c|}
\hline \multirow[t]{2}{*}{ Characteristic } & \multicolumn{2}{|c|}{ Weekly Group } & \multicolumn{2}{|c|}{ Triweekly Group } & \multicolumn{2}{|l|}{ Total } & \multirow[t]{2}{*}{ P } \\
\hline & No. & $\%$ & No. & $\%$ & No. & $\%$ & \\
\hline Age & & & & & & & $0.985^{b}$ \\
\hline$\leq 44$ & 47 & 50.5 & 116 & 50.7 & 163 & 50.6 & \\
\hline$>44$ & 46 & 49.5 & 113 & 49.3 & 159 & 49.4 & \\
\hline Sex & & & & & & & $0.076^{\mathrm{b}}$ \\
\hline Male & 83 & 89.2 & 217 & 94.8 & 300 & 93.2 & \\
\hline Female & 10 & 10.8 & 12 & 5.2 & 22 & 6.8 & \\
\hline Smoking & & & & & & & $0.915^{b}$ \\
\hline No & 74 & 79.6 & 181 & 79.0 & 255 & 79.2 & \\
\hline Yes & 19 & 20.4 & 48 & 21.0 & 67 & 20.8 & \\
\hline Drink & & & & & & & $0.201^{b}$ \\
\hline No & 91 & 97.8 & 228 & 99.6 & 319 & 99.1 & \\
\hline Yes & 2 & 2.2 & 1 & 0.4 & 3 & 0.9 & \\
\hline Histology ${ }^{a}$ & & & & & & & $0.560^{b}$ \\
\hline Non-keratinizing Undifferentiated (type III) & 93 & 100 & 226 & 98.7 & 319 & 99.1 & \\
\hline Others (type I and II) & 0 & 0 & 3 & 1.3 & 3 & 0.9 & \\
\hline T stage $\left(8^{\text {th }} \mathrm{AJCC}\right)$ & & & & & & & $0.941^{b}$ \\
\hline $\mathrm{T} 1-2$ & 39 & 41.9 & 95 & 41.5 & 134 & 41.6 & \\
\hline T3-4 & 54 & 58.1 & 134 & 58.5 & 188 & 58.4 & \\
\hline$N$ stage $\left(8^{\text {th }} \mathrm{AJCC}\right)$ & & & & & & & $0.172^{\mathrm{b}}$ \\
\hline No-1 & 80 & 86.0 & 182 & 79.5 & 262 & 81.4 & \\
\hline N2-3 & 13 & 14.0 & 47 & 20.5 & 60 & 18.6 & \\
\hline Stage $\left(8^{\text {th }}\right.$ AJCC $)$ & & & & & & & $0.475^{\mathrm{b}}$ \\
\hline$|-| \mid$ & 36 & 38.7 & 79 & 34.5 & 115 & 35.7 & \\
\hline III-IVA & 57 & 61.3 & 150 & 65.5 & 207 & 64.3 & \\
\hline EBV & & & & & & & $0.621^{b}$ \\
\hline$\leq 4000 \mathrm{copy} / \mathrm{ml}$ & 62 & 66.7 & 146 & 63.8 & 208 & 64.6 & \\
\hline$>4000$ copy/ml & 31 & 33.3 & 83 & 36.2 & 114 & 35.4 & \\
\hline Cumulative cisplatin & 190.54 & $53.27^{d}$ & 202.97 & $54.39^{d}$ & & & $0.062^{c}$ \\
\hline
\end{tabular}

Abbreviations: $T$ NPC tumor stage, $N$ nodal stage, CCRT concurrent chemoradiotherapy, AJCC American Joint Committee on Cancer, EBV Epstein-Barr virus

${ }^{a}$ Histology was categorized according to the WHO Classification of Tumors

${ }^{\mathrm{b}} \mathrm{Chi}$-square test or Fisher's exact test

'Student's $t$-test

${ }^{\mathrm{d}}$ Standard deviation

EBV DNA load ( $\leq 4000$ copies/ml vs. $>4000$ copies $/ \mathrm{ml}$, $\mathrm{HR}=2.365,95 \% \mathrm{CI}=1.355-4.126, P=0.002)$ and node (N) classification (N0-1 vs. $\mathrm{N} 2-3, \mathrm{HR}=2.18,95 \% \mathrm{CI}=$ 1.157-4.109, $P=0.016$ ) were independent prognostic indicators. The regimen of cisplatin delivery (weekly vs. triweekly, $\mathrm{HR}=2.071,95 \% \mathrm{CI}=0.969-4.426, \quad P=0.06$ ) was not an independent prognostic factor for DFS (Table 3). Regarding LRFS (weekly vs. triweekly, $\mathrm{HR}=2.665$, 95\% CI $=0.788-9.005, P=0.115$ ) and DMFS (weekly vs. triweekly, $\mathrm{HR}=1.985,95 \% \mathrm{CI}=0.57-6.908, P=0.281)$ in univariate analyses, the cisplatin delivery regimen was ineligible for inclusion in the multivariate analysis.

\section{Subgroup analyses}

In the entire cohort, 207 (64.3\%) patients had Stage-IIIIVA disease, including 57 (61.3\%) patients in the Weekly
Group and 150 (65.5\%) in the Triweekly Group. The 5 -year DFS of Stage-III-IVA patients in the Weekly Group was better than that of Stage-III-IVA patients in the Triweekly Group (weekly vs. triweekly, $88.5 \%$ vs. $74 \%$, $\chi^{2}=4.991, P=0.025$; Fig. 2 b), which was statistically significant. The weekly and triweekly 5 -year OS rates were 94.6 and $83.7 \%\left(X^{2}=3.259, P=0.071\right)$ (Fig. 2a), the weekly and triweekly 5-year DMFS rates were 96.4 and $88.3 \%\left(\chi^{2}\right.$ $=3.004, P=0.083$ Fig. $2 \mathrm{c}$ ), and the weekly and triweekly 5-year LRFS rates were 95.9 and $90.6 \%\left(\chi^{2}=1.923, P=\right.$ 0.166 Fig. $2 d$ ). The log-rank test revealed that there were no significant differences in the 5-year DMFS and 5-year LRFS rates between the groups (Fig. 2). For patients with Stage-I-II disease, the weekly vs. triweekly survival end-points were as follows: 5-year OS, $100 \%$ vs. $97.1 \%\left(x^{2}\right.$ $=0.875, P=0.35)$; 5 -year DMFS, $97.1 \%$ vs. $97.2 \%\left(X^{2}=\right.$ 

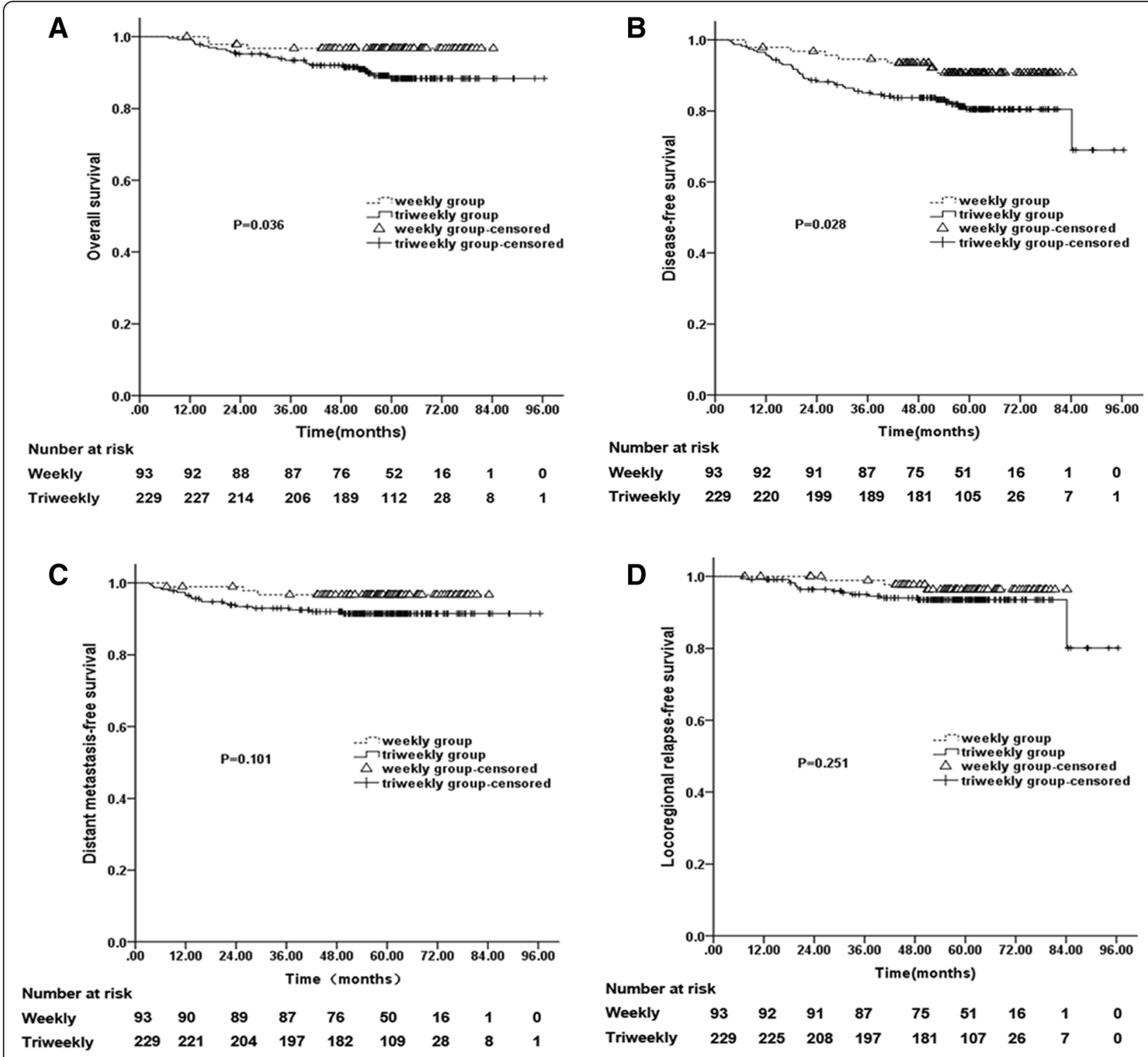

Fig. 1 Survival curves for patients with NPC. The overall survival (OS) curves showed that the Weekly group was better than Triweekly group $(P=$ 0.036, there was a significant difference between the groups) (a). The disease-free survival (DFS) curves showed that the Weekly group was better than the Triweekly group ( $P=0.028$, there was a significant difference between the groups) (b). The distant metastasis-free survival (DMFS) curves (c) and the locoregional relapse-free survival (LRFS) curves (d) revealed no significant difference between the two groups

0.008, $P=0.929)$; 5 -year LRFS, $97.1 \%$ vs. $98.7 \%\left(\chi^{2}=0.303\right.$, $P=0.582)$; and 5-year DFS, $94.3 \%$ vs. $92.6 \%\left(\chi^{2}=0.025, P\right.$ $=0.874)$. The log-rank test revealed that there were no significant differences in survival outcomes.

\section{Discussion}

We noticed that the Weekly and Triweekly Groups had similar 5-year DMFS and LRFS rates in this retrospective study. Our results are in agreement with previous studies [13-15], which showed that $40 \mathrm{mg} / \mathrm{m}^{2}$ of cisplatin weekly and $100 \mathrm{mg} / \mathrm{m}^{2}$ of cisplatin triweekly had similar deliverabilities and outcomes. Also, we found that the 5-year OS and DFS rates of the Weekly Group were better than those of the Triweekly Group, and that the 5-year DFS of patients with Stage-III-IVA disease was better in the Weekly Group than in the Triweekly Group. These results differ from those of previous studies [13-15]. Of course, the patients selected by us differed from those selected in previous studies. All the patients in the studies by Jagdis et al. and Lee et al. [13, 14] and some of the patients in the study by Tao et al. [15] received CCRT plus AC with cisplatin and 5-fluorouracil, whereas our patients received CCRT alone. Furthermore, a small proportion of patients in 
Table 2 Treatment related toxicities

\begin{tabular}{|c|c|c|c|c|c|}
\hline \multirow[t]{2}{*}{ Toxicities } & \multicolumn{2}{|c|}{ Weekly } & \multicolumn{2}{|c|}{ Triweekly } & \multirow[t]{2}{*}{$P^{*}$} \\
\hline & No. & $\%$ & No. & $\%$ & \\
\hline \multicolumn{6}{|l|}{ Hematologic } \\
\hline Thrombocytopenia & & & & & 0.120 \\
\hline$<\mathrm{G} 3$ & 86 & 92.5 & 221 & 96.5 & \\
\hline$\geq \mathrm{G} 3$ & 7 & 7.5 & 8 & 3.5 & \\
\hline Anemia & & & & & 0.147 \\
\hline$<\mathrm{G} 3$ & 91 & 97.8 & 228 & 99.6 & \\
\hline$\geq \mathrm{G} 3$ & 2 & 2.2 & 1 & 0.4 & \\
\hline Leucopenia & & & & & 0.208 \\
\hline$<\mathrm{G} 3$ & 72 & 77.4 & 191 & 83.4 & \\
\hline$\geq \mathrm{G} 3$ & 21 & 22.6 & 38 & 16.6 & \\
\hline \multicolumn{6}{|l|}{ Non-hematologic } \\
\hline Mucosa & & & & & 0.170 \\
\hline$<\mathrm{G} 3$ & 89 & 95.7 & 209 & 91.3 & \\
\hline$\geq \mathrm{G} 3$ & 4 & 4.3 & 20 & 8.7 & \\
\hline Skin & & & & & 1.000 \\
\hline$<\mathrm{G} 3$ & 92 & 98.9 & 227 & 99.1 & \\
\hline$\geq \mathrm{G} 3$ & 1 & 1.1 & 2 & 0.9 & \\
\hline Nausea-vomiting & & & & & 0.786 \\
\hline$<\mathrm{G} 3$ & 89 & 95.7 & 216 & 94.3 & \\
\hline$\geq \mathrm{G} 3$ & 4 & 4.3 & 13 & 5.7 & \\
\hline Creatinine-increased & & & & & 0.289 \\
\hline$<\mathrm{G} 3$ & 92 & 98.9 & 229 & 100.0 & \\
\hline$\geq \mathrm{G} 3$ & 1 & 1.1 & 0 & 0.0 & \\
\hline Ototoxicity & & & & & 1.000 \\
\hline$<\mathrm{G} 3$ & 93 & 100.0 & 227 & 99.1 & \\
\hline$\geq \mathrm{G} 3$ & 0 & 0.0 & 2 & 0.9 & \\
\hline
\end{tabular}

Abbreviations: $G$ grade

${ }^{*}$ Chi-square test or Fisher's exact test
Table 3 Multivariate analyses in the overall population

\begin{tabular}{llll}
\hline Variable & HR & $95 \% \mathrm{Cl}$ & $P^{*}$ \\
\hline OS & & & \\
EBV & 3.402 & $1.525-7.589$ & 0.003 \\
$\quad$ Cisplatin regimen & 2.795 & $0.836-9.350$ & 0.095 \\
DFS & & & \\
EBV & 2.365 & $1.355-4.126$ & 0.002 \\
N stage & 2.180 & $1.157-4.109$ & 0.016 \\
Cisplatin regimen & 2.071 & $0.969-4.426$ & 0.060 \\
\hline
\end{tabular}

Abbreviations: OS overall survival, EBV Epstein-Barr virus, DFS disease-free survival, $\mathrm{Cl}$ confidence interval, $H R$ hazard ratio

${ }^{*}$ Chi-square test or Fisher's exact test these three earlier studies received three-dimensional conformal radiotherapy (3D-CRT), but in our study, all patients received IMRT. Besides, previous reports have shown that DFS is better following IMRT than following $3 \mathrm{D}-\mathrm{CRT}[21,22]$. In our study, the survival outcomes were obviously improved compared with those of previous trials $[4,6,10]$, which may have been the result of improvements in RT technology, advances in treatment after relapse, and the application of targeted therapy [23-27].

Traditionally, it was thought that more frequent use of smaller doses of cisplatin would produce a lower toxicity profile while maintaining efficacy. This is consistent with the findings of Rampino et al. [12]. Notably, the incidence of Grade 3-4 toxic events was not lower among patients in the Weekly Group than among patients in the Triweekly Group in this study, which is in accordance with the conclusions of Ho et al. [28]. Grade 3-4 toxic events were more frequent in the Triweekly Group (53.3\%) than in the Weekly Group (40\%), but without statistical significance, in a study by Uygun et al. [29]. In contrast, the KCSG-HN10-02 trial found that the weekly cisplatin regimen caused a higher incidence of severe thrombocytopenia than the triweekly regimen (7.5\% vs. $1.8 \%, P=0.198)$ [14]. Tao et al. showed that Grade 3-4 hematologic toxic events were more common in the Weekly Group than in the Triweekly Group, but without statistical significance [15]. In this study, more patients in the Weekly Group than in the Triweekly Group exhibited severe hematologic toxic events, including thrombocytopenia (weekly vs. triweekly, $7.5 \%$ vs. $3.5 \%, P=$ 0.12 ), anemia (weekly vs. triweekly, $2.2 \%$ vs. $0.4 \%, P=$ 0.147 ), and leucopenia (weekly vs. triweekly, $22.6 \%$ vs. $16.6 \%, P=0.208$ ), but without statistical significance. Every patient was required to undergo assessments of hematologic, renal, and hepatic functions before chemotherapy, but patients in the Weekly Group were evaluated more frequently than patients in the Triweekly Group. This may have delayed the identification of severe advanced events in the Triweekly Group, and may represent an undefined bias regarding toxicity profiles.

The multivariate analysis conclusion that pre-treatment EBV DNA load and N classification are independent prognostic factors has been confirmed by past study [20]. Part of our results differ from those of the KCSG-HN10-02 trial and the studies by Jagdis et al. and Tao et al. [13-15]. We attribute these differences to variations in the study populations, sample sizes, and follow-up durations, and to advances in therapeutic techniques. Canada and Korea do not have high incidences of NPC, meaning that the number of patients is low [13, 14]. Sun Yat-sen University Cancer Center is in south-eastern China, an area with a high prevalence of NPC, and has the highest number of clinical patients with NPC worldwide. In our study, the size of the 

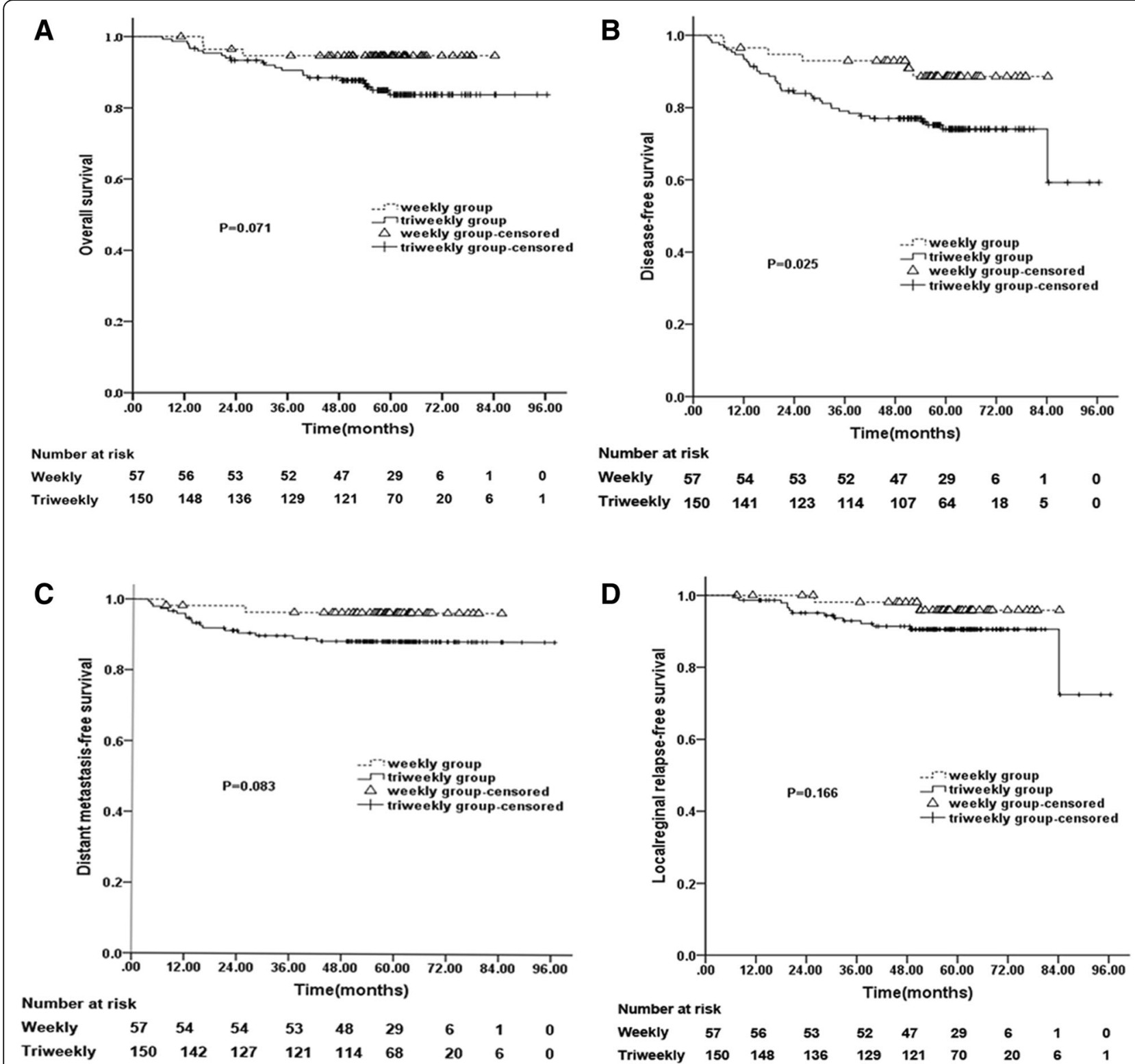

Fig. $\mathbf{2}$ Survival curves for patients with Stage-III-IVA NPC. The OS curves showed there was no significant difference between the two groups (a). The DFS curves showed that the Weekly group was better than the Triweekly group ( $P=0.025$, there was a significant difference between the groups) (b). The DMFS (c) and LRFS (d) curves showed no significant differences between the two groups

sample was 322, the patients received treatment with CCRT alone, and the median follow-up time for the entire cohort was 60.2 months (range, 7-96.4 months), beyond which we have continued to follow-up our patients.

This retrospective study has several limitations. First, major limitations, including its retrospective nature, potential selection bias, information bias, and confounding bias, were unavoidable. Second, this study was performed at a single-center located in an area in which NPC is endemic. The main histology of the selected patients was undifferentiated, non-keratinizing carcinoma. Whether our results are applicable to Western countries such as in Europe and North America, where the incidence of NPC is relatively low, remains unclear. Third, our study used simple tumor-nodes-metastasis staging, and did not involve a more detailed subgroup analysis based on patients' characteristics. Multicenter, prospective, large-scale, randomized controlled trials are necessary to determine the optimal cisplatin regimen during CCRT for the treatment of NPC.

\section{Conclusions}

The incidence of severe acute toxicities was similar between the two groups, whereas the Weekly Group had 
better performance in OS and DFS than the Triweekly Group. Besides, with the weekly regimen, patients were able to choose outpatient treatment without essential hydration. Thus, the weekly cisplatin regimen may be a better choice during CCRT for the treatment of NPC; prospective randomized controlled clinical trials are needed to confirm this conclusion.

\section{Abbreviations}

3D-CRT: Three-dimensional conformal radiotherapy; AC: Adjuvant chemotherapy; AJCC: American Joint Committee on Cancer; CCRT: Concurrent chemoradiotherapy; Cl: Confidence interval; DFS: Diseasefree survival; DMFS: Distant metastasis-free survival; EBV: Epstein-Barr virus; HR: Hazard ratio; IMRT: Intensity-modulated radiation therapy; LRFS: Locoregional relapse-free survival; N: Node; NPC: Nasopharyngeal carcinoma; OS: Overall survival; RT: Radiotherapy

\section{Acknowledgments}

We thank the native English-speaking scientists of Elixigen Company (Huntington Beach, California) for editing our manuscript.

\section{Funding}

This work was supported by the Natural Science Foundation of Guangdong Province, China [grant number 2017A030313764] and the Guangdong Medical Research Foundation [grant number A2016011]. The funding agencies had no role in the study design, data collection and analysis, decision to publish, or preparation of the manuscript.

\section{Availability of data and materials}

Because of the scientific research requirement of the Sun Yat-sen University Cancer Center, the authenticity of this article has been validated by uploading the key raw data onto the Research Data Deposit public platform (www. researchdata.org.cn), with the approval RDD number as RDDA2018000818, and the identifying/confidential patient data has been hidden.

\section{Authors' contributions}

KW and JD wrote the main manuscript text; SH and $\mathrm{CJ}$ collected and analyzed the data and prepared the revised manuscript. PH, XW1 and JG prepared Figures; KW prepared Tables. JD, XC, and XW2 made responses to the reviewers. All authors have read and approved the manuscript.

\section{Ethics approval and consent to participate}

Research Ethics Committee of Sun Yat-sen University Cancer Center have approved this study. All patients have signed the informed consent after clearly understood the purpose and risks of this study.

\section{Consent for publication}

Not applicable.

\section{Competing interests}

The authors declare that they have no competing interests.

\section{Publisher's Note}

Springer Nature remains neutral with regard to jurisdictional claims in published maps and institutional affiliations.

\footnotetext{
Author details

'Department of Oncology, The First Affiliated Hospital of Guangdong Pharmaceutical University, Guangdong Pharmaceutical University, 19 Nonglinxia Road, Guangzhou 510062, China. ${ }^{2}$ Department of Integrated Therapy in Oncology, Sun Yat-sen University Cancer Center, State Key Laboratory of Oncology in South China, Collaborative Innovation Center for Cancer Medicine, Guangdong Key Laboratory of Nasopharyngeal Carcinoma Diagnosis and Therapy, 651 East Dongfeng Road, Guangzhou 510060, China. ${ }^{3}$ Department of Radiation, Sun Yat-sen University Cancer Center; State Key Laboratory of Oncology in South China; Collaborative Innovation Center for Cancer Medicine, Guangdong Key Laboratory of Nasopharyngeal Carcinoma Diagnosis and Therapy, Guangzhou 510060, China. ${ }^{4}$ Department of Radiation Oncology, The First People's Hospital of Foshan, Foshan 528000, China.
}

Received: 5 November 2018 Accepted: 8 May 2019

Published online: 22 May 2019

\section{References}

1. Torre LA, Bray F, Siegel RL, Ferlay J, Lortet-Tieulent J, Jemal A. Global cancer statistics, 2012. CA Cancer J Clin. 2015;65(2):87-108.

2. Wei Wl, Sham JS. Present status of management of nasopharyngeal carcinoma. Expert Rev Anticancer Ther. 2001;1(1):134-41.

3. Wei WI, Sham JS. Nasopharyngeal carcinoma. Lancet. 2005;365(9476):204154.

4. Baujat B, Audry H, Bourhis J, Chan AT, Onat H, Chua DT, Kwong DL, Al-Sarraf M, Chi KH, Hareyama M, et al. Chemotherapy in locally advanced nasopharyngeal carcinoma: an individual patient data meta-analysis of eight randomized trials and 1753 patients. Int J Radiat Oncol Biol Phys. 2006;64(1): 47-56.

5. He J, Wu P, Tang Y, Liu S, Xie C, Luo S, Zeng J, Xu J, Zhao S. Chemoradiotherapy enhanced the efficacy of radiotherapy in nasopharyngeal carcinoma patients: a network meta-analysis. Oncotarget. 2017:8(24):39782-94.

6. Lee AW, Tung SY, Chan AT, Chappell R, Fu YT, Lu TX, Tan T, Chua DT, O'Sullivan B, Xu SL, et al. Preliminary results of a randomized study (NPC9902 trial) on therapeutic gain by concurrent chemotherapy and/or accelerated fractionation for locally advanced nasopharyngeal carcinoma. Int J Radiat Oncol Biol Phys. 2006;66(1):142-51.

7. Lee AW, Tung SY, Chua DT, Ngan RK, Chappell R, Tung R, Siu L, Ng WT, Sze WK, Au GK, et al. Randomized trial of radiotherapy plus concurrent-adjuvant chemotherapy vs radiotherapy alone for regionally advanced nasopharyngeal carcinoma. J Natl Cancer Inst. 2010;102(15):1188-98.

8. Chen Y, Sun Y, Liang SB, Zong JF, Li WF, Chen M, Chen L, Mao YP, Tang LL, Guo $Y$, et al. Progress report of a randomized trial comparing long-term survival and late toxicity of concurrent chemoradiotherapy with adjuvant chemotherapy versus radiotherapy alone in patients with stage III to IVB nasopharyngeal carcinoma from endemic regions of China. Cancer. 2013; 119(12):2230-8.

9. Lee AW, Lau WH, Tung SY, Chua DT, Chappell R, Xu L, Siu L, Sze WM, Leung TW, Sham JS, et al. Preliminary results of a randomized study on therapeutic gain by concurrent chemotherapy for regionally-advanced nasopharyngeal carcinoma: NPC-9901 trial by the Hong Kong nasopharyngeal Cancer study group. J Clin Oncol Off J Am Soc Clin Oncol. 2005;23(28):6966-75.

10. Al-Sarraf M, LeBlanc M, Giri PG, Fu KK, Cooper J, Vuong T, Forastiere AA, Adams G, Sakr WA, Schuller DE, et al. Chemoradiotherapy versus radiotherapy in patients with advanced nasopharyngeal cancer: phase III randomized intergroup study 0099. J Clin Oncol Off J Am Soc Clin Oncol. 1998;16(4):1310-7.

11. Chan AT, Leung SF, Ngan RK, Teo PM, Lau WH, Kwan WH, Hui EP, Yiu HY, Yeo W, Cheung FY, et al. Overall survival after concurrent cisplatinradiotherapy compared with radiotherapy alone in locoregionally advanced nasopharyngeal carcinoma. J Natl Cancer Inst. 2005:97(7):536-9.

12. Rampino M, Ricardi U, Munoz F, Reali A, Barone C, Musu AR, Balcet V, Franco P, Grillo R, Bustreo S, et al. Concomitant adjuvant chemoradiotherapy with weekly low-dose cisplatin for high-risk squamous cell carcinoma of the head and neck: a phase II prospective trial. Clin Oncol. 2011;23(2):134-40

13. Jagdis A, Laskin J, Hao D, Hay J, Wu J, Ho C. Dose delivery analysis of weekly versus 3-weekly cisplatin concurrent with radiation therapy for locally advanced nasopharyngeal carcinoma (NPC). Am J Clin Oncol. 2014; 37(1):63-9.

14. Lee JY, Sun JM, Oh DR, Lim SH, Goo J, Lee SH, Kim SB, Park KU, Kim HK, Hong DS, et al. Comparison of weekly versus triweekly cisplatin delivered concurrently with radiation therapy in patients with locally advanced nasopharyngeal cancer: a multicenter randomized phase II trial (KCSGHN10-02). Radiother Oncol. 2016;118(2):244-50.

15. Tao CJ, Lin L, Zhou GQ, Tang LL, Chen L, Mao YP, Zeng MS, Kang TB, Jia $\mathrm{WH}$, Shao JY, et al. Comparison of long-term survival and toxicity of cisplatin delivered weekly versus every three weeks concurrently with intensity-modulated radiotherapy in nasopharyngeal carcinoma. PLoS One. 2014;9(10):e110765.

16. Amin MB. American joint committee on Cancer staging manual, 8 edn: springer international publishing; 2017.

17. Chen A, Lee N, Yang C, Liu T, Narayan S, Vijayakumar S, Purdy J. Comparison of intensity-modulated radiotherapy using helical tomotherapy and 
segmental multileaf collimator-based techniques for nasopharyngeal carcinoma: dosimetric analysis incorporating quality assurance guidelines from RTOG 0225. Technol Cancer Res Treat. 2010;9(3):291-8.

18. Common Terminology Criteria for Adverse Events v.3.0and v.4.0 (CTCAE). Available at: http: // ctep.cancer.gov / protocol Development / electronic_ applications / ctc.htm.

19. He SS, Wang Y, Yang L, Chen HY, Liang SB, Lu LX, Chen Y. Plasma fibrinogen correlates with metastasis and is associated with prognosis in human nasopharyngeal carcinoma. J Cancer. 2017;8(3):403-9.

20. Tang LQ, Chen QY, Fan W, Liu H, Zhang L, Guo L, Luo DH, Huang PY, Zhang $X$, Lin XP, et al. Prospective study of tailoring whole-body dual-modality [18F] fluorodeoxyglucose positron emission tomography/computed tomography with plasma Epstein-Barr virus DNA for detecting distant metastasis in endemic nasopharyngeal carcinoma at initial staging. J Clin Oncol Off J Am Soc Clin Oncol. 2013:31(23):2861-9.

21. Pow EH, Kwong DL, McMillan AS, Wong MC, Sham JS, Leung LH, Leung WK. Xerostomia and quality of life after intensity-modulated radiotherapy vs. conventional radiotherapy for early-stage nasopharyngeal carcinoma: initial report on a randomized controlled clinical trial. Int J Radiat Oncol Biol Phys. 2006;66(4):981-91.

22. Wolden SL, Chen WC, Pfister DG, Kraus DH, Berry SL, Zelefsky MJ. Intensitymodulated radiation therapy (IMRT) for nasopharynx cancer: update of the memorial Sloan-Kettering experience. Int J Radiat Oncol Biol Phys. 2006; 64(1):57-62.

23. Ferris RL, Blumenschein G Jr, Fayette J, Guigay J, Colevas AD, Licitra L, Harrington K, Kasper S, Vokes EE, Even C, et al. Nivolumab for recurrent squamous-cell carcinoma of the head and neck. N Engl J Med. 2016;375(19): 1856-67.

24. Xiao WW, Huang SM, Han F, Wu SX, Lu LX, Lin CG, Deng XW, Lu TX, Cui NJ, Zhao C. Local control, survival, and late toxicities of locally advanced nasopharyngeal carcinoma treated by simultaneous modulated accelerated radiotherapy combined with cisplatin concurrent chemotherapy: long-term results of a phase 2 study. Cancer. 2011;117(9):1874-83.

25. Lai SZ, Li WF, Chen L, Luo W, Chen YY, Liu LZ, Sun Y, Lin AH, Liu MZ, Ma J. How does intensity-modulated radiotherapy versus conventional twodimensional radiotherapy influence the treatment results in nasopharyngeal carcinoma patients? Int J Radiat Oncol Biol Phys. 2011;80(3):661-8.

26. Zhang L, Huang Y, Hong S, Yang Y, Yu G, Jia J, Peng P, Wu X, Lin Q, Xi X, et al. Gemcitabine plus cisplatin versus fluorouracil plus cisplatin in recurrent or metastatic nasopharyngeal carcinoma: a multicentre, randomised, openlabel, phase 3 trial. The Lancet. 2016;388(10054):1883-92.

27. Seiwert TY, Burtness B, Mehra R, Weiss J, Berger R, Eder JP, Heath K, McClanahan T, Lunceford J, Gause C, et al. Safety and clinical activity of pembrolizumab for treatment of recurrent or metastatic squamous cell carcinoma of the head and neck (KEYNOTE-012): an open-label, multicentre, phase 1b trial. Lancet Oncol. 2016;17(7):956-65.

28. Ho KF, Swindell R, Brammer CV. Dose intensity comparison between weekly and 3-weekly cisplatin delivered concurrently with radical radiotherapy for head and neck cancer: a retrospective comparison from new cross hospital, Wolverhampton, UK. Acta Oncol. 2008;47(8):1513-8.

29. Uygun K, Bilici A, Karagol H, Caloglu M, Cicin I, Aksu G, Fayda M, Uzunoglu $\mathrm{S}$. The comparison of weekly and three-weekly cisplatin chemotherapy concurrent with radiotherapy in patients with previously untreated inoperable non-metastatic squamous cell carcinoma of the head and neck. Cancer Chemother Pharmacol. 2009:64(3):601-5.

Ready to submit your research? Choose BMC and benefit from:

- fast, convenient online submission

- thorough peer review by experienced researchers in your field

- rapid publication on acceptance

- support for research data, including large and complex data types

- gold Open Access which fosters wider collaboration and increased citations

- maximum visibility for your research: over $100 \mathrm{M}$ website views per year

At BMC, research is always in progress.

Learn more biomedcentral.com/submissions 